\title{
Do correlates of HPV vaccine initiation differ between adolescent boys and girls?
}

\author{
Melissa B. Gilkey, PhDa, Jennifer L. Moss ${ }^{b}$, Annie-Laurie McRee, DrPH ${ }^{c}$, and Noel T. \\ Brewer, PhD ${ }^{d}$ \\ Melissa B. Gilkey: gilkey@email.unc.edu; Jennifer L. Moss: jlmoss@email.unc.edu; Annie-Laurie McRee: \\ almcree@umn.edu; Noel T. Brewer: ntb@unc.edu \\ aLineberger Comprehensive Cancer Center, University of North Carolina; CB\# 7440; Chapel Hill, \\ NC 27599 USA; Phone: 919-942-8083; Fax: 919-966-2921 \\ bGillings School of Global Public Health, University of North Carolina; CB\# 7440; Chapel Hill, NC \\ 27599 USA \\ 'Department of Pediatrics, University of Minnesota; 717 Delaware St SE, $3^{\text {rd }}$ Floor; Minneapolis, \\ MN 55414 USA \\ ${ }^{d}$ Gillings School of Global Public Health, University of North Carolina; CB\# 7440; Chapel Hill, NC \\ 27599 USA
}

\section{Abstract}

Background-Guidelines now recommend that adolescents routinely receive human papillomavirus (HPV) vaccine. Because little is known about uptake among boys, we assessed HPV vaccine initiation in a population-based sample of adolescent boys and girls.

Methods-We analyzed weighted data from 751 parents who reported on an 11- to 17-year-old son or daughter for the 2010 North Carolina Child Health Assessment and Monitoring Program survey. Stratified multivariate logistic regression analyses identified correlates of HPV vaccine initiation separately for boys and girls.

Results-Only $14 \%$ of sons had received one or more doses of HPV vaccine compared to $44 \%$ of daughters $(p<0.01)$. For both sons and daughters, vaccine initiation correlated with age and having received meningococcal vaccine. Among sons, initiation of HPV vaccine was lower for those living in high income households (odds ratio $[\mathrm{OR}]=0.22,95 \% \mathrm{CI}, 0.09-0.53$ ) and higher for those whose race was neither white nor black (OR=3.26, 95\% CI, 1.06-10.04). When asked to give the main reason for not vaccinating their child against HPV, parents of unvaccinated sons were more likely than those of daughters to report not getting a provider's recommendation or not being aware the vaccine was available for their child, but less likely to report concern about safety $(p<0.01)$. At least $86 \%$ of unvaccinated children had missed an opportunity to receive HPV vaccine.

Conclusions-HPV vaccine correlates and concerns varied for parents of boys and girls. To improve very low levels of uptake among boys, providers should recommend HPV vaccine concomitant with other adolescent vaccines.

(C) 2012 Elsevier Ltd. All rights reserved.

Correspondence to: Melissa B. Gilkey, gilkey@email . unc. edu; Noel T. Brewer, ntb@unc. edu.

Publisher's Disclaimer: This is a PDF file of an unedited manuscript that has been accepted for publication. As a service to our customers we are providing this early version of the manuscript. The manuscript will undergo copyediting, typesetting, and review of the resulting proof before it is published in its final citable form. Please note that during the production process errors may be discovered which could affect the content, and all legal disclaimers that apply to the journal pertain. 


\section{Keywords}

adolescent health; human papillomavirus infections/prevention \& control; vaccination/statistics \& numerical data; North Carolina

Since 2006 the Centers for Disease Control and Prevention (CDC) has recommended routinely providing human papillomavirus (HPV) vaccine to adolescent females as a strategy for preventing genital warts and several types of cancer [1]. In October 2011, the agency extended this recommendation to cover adolescent males, thereby strengthening the previous "permissive recommendation" the vaccine received when first approved for this population in 2009 [2]. The more recent guidelines call for routine vaccination of 11- to 12year-old boys, with 9- to 21-year-old males considered age-eligible [2]. Guidelines for females are similar, but extend to 26 years of age [1].

Achieving widespread HPV vaccination among males will require surveillance to track coverage and identify modifiable correlates of uptake. Although a small body of existing research characterizes knowledge and attitudes related to HPV vaccination among males [310], less is currently known about uptake in this population. Using national samples, two studies conducted in 2010 found that, in the first year after licensure, only $1-2 \%$ of adolescent boys had received at least one dose of HPV vaccine [11-12]. Existing research identifies correlates of HPV vaccine uptake among females [13-17], but to our knowledge, no published studies address this question for adolescent males. Because factors such as perceived benefit of HPV vaccine differ by child's sex [4], we cannot assume that correlates of uptake among boys will mirror those of girls.

To address gaps in the literature, we used data from a statewide survey to: (a) characterize HPV vaccine initiation among adolescent males and females using a population-based sample; (b) assess missed opportunities for providing HPV vaccine; and (c) assess the main reason parents reported for not getting their child HPV vaccine. By investigating how HPV vaccination differs by child's sex, this study aims to inform the development of targeted strategies for increasing vaccine uptake and lowering the burden of HPV infection among adolescents.

\section{METHODS}

Participants

We used data from two state-based telephone surveys conducted in North Carolina in 2010: the Behavioral Risk Factor Surveillance System (BRFSS) survey and the Child Health Assessment and Monitoring Program (CHAMP) survey. North Carolina BRFSS is an annual population-based survey of adults contacted through random-digit dialing [18]. If a 2010 BRFSS respondent reported living in a household with a child under 18 years of age, that household became eligible for CHAMP, a follow-up survey offered in English and Spanish [19]. The adult caregiver identified as being most knowledgeable about the child's health completed CHAMP. For households with multiple children, survey software randomly selected an index child to be the focus of the survey. Unique identifiers linked data from BRFSS respondents and CHAMP caregivers at the household level. Because most caregivers (87\%) reported being the biological parent of the index child, we refer to CHAMP respondents as "parents."

The response rate for the 2010 North Carolina BRFSS survey was $61 \%$ of 20,208 eligible households as estimated by the Council of American Research Organization (CASRO) response rate calculation [20]. Of the 3,174 BRFSS parents asked to participate in CHAMP, 
2,009 (63\%) completed the survey. Because guidelines recommend HPV vaccination for 11to 12-year-olds with older adolescents eligible for "catch up" immunization, we focused this study on children ages 11 through 17 . We excluded data from 1,258 (63\%) parents, including: those whose index child was not age $11-17$ years $(n=1,057)$; those who had not heard of HPV vaccine ( $n=152)$; and those who were unsure whether their child had received HPV vaccine or who declined to answer $(n=49)$ (Figure 1). Our analytic sample consisted of the remaining 751 parents, of whom 359 (48\%) reported on a male index child and 392 $(52 \%)$ reported on a female index child. Overall, 20 parents completed the survey in Spanish. The University of North Carolina Institutional Review Board determined that this analysis was exempt from review.

\section{Measures}

The CHAMP survey assessed HPV vaccine initiation with a single item: "Has (CHILD'S NAME) had any shots of the HPV vaccine?" Interviewers asked parents of unvaccinated adolescents to identify the main reason the child had not been vaccinated against HPV. CHAMP also assessed other healthcare-related variables, including whether the child had: health insurance coverage; a regular healthcare provider; a preventive care visit in the previous year; or ever received meningitis vaccine or a tetanus shot. The survey also assessed the child's sex, age, race, and school type as well as the highest level of education attained by anyone in the household and sex of the parent completing the interview.

The BRFSS survey assessed additional parent information, including age, employment status, and receipt of seasonal flu vaccine (shot or nasal spray) in the previous year. BRFSS respondents also indicated household income and the total number of children living in the household. We defined households located within a metropolitan statistical area (MSA) as "urban" and those outside an MSA as "rural" [21].

\section{Statistical Analyses}

We used logistic regression to identify bivariate correlates of HPV vaccine initiation for male and female adolescents separately. We then entered statistically significant $(p<0.05)$ correlates into multivariate models. To assess "missed opportunities" for receiving HPV vaccine, we calculated the percentage of unvaccinated boys $(n=316)$ and girls $(n=218)$ who had received a recent preventive care visit or meningococcal vaccine. We used Pearson's chi-squared tests to compare parents' main reason for not getting their children vaccinated against HPV, analyzing reasons separately for sons $(n=314)$ and daughters $(n=215)$; these analyses excluded 5 parents who did not give a reason. We analyzed data using Stata Version 12.0 (Statacorp, College Station, TX), incorporating sample weights to account for the study design. We report unweighted frequencies and weighted proportions, odds ratios, and confidence intervals. All statistical tests were 2-tailed with a critical alpha of 0.05 .

\section{RESULTS}

\section{Sample Characteristics}

Sons and daughters did not differ on any of the thirteen sample characteristics assessed (Table 1). The mean age for sons and daughters was 14.0 years. Most parents reported on children who were non-Hispanic white $(69 \%)$ or black (20\%), and we collapsed the remaining racial/ethnic designations into a third category of "other" $(12 \%)$, which included children parents identified as Hispanic or Latino $(n=48)$, American Indian or Alaska Native $(n=14)$, Asian $(n=5)$, multiracial $(n=4)$, or some other race $(n=11)$. The majority of parents indicated that their child attended public school (90\%), was covered by some form of health insurance (95\%), had a regular healthcare provider (82\%), and had received a preventive check-up in the last year $(83 \%)$. 
Parents' mean age was 44 years. Most parents were female (88\%) and employed (69\%), and about half reported an annual household income of $\$ 50,000$ or more (54\%). Most households included more than one child $(70 \%)$, as well as at least one family member with some college education (81\%). About three quarters of households (74\%) were located in an urban area.

\section{HPV Vaccine Initiation}

Just $14 \%$ of parents of sons reported their child had received one or more doses of HPV vaccine compared to $44 \%$ of parents of daughters $(p<0.01)$. In bivariate and multivariate analyses (Tables 2 and 3), vaccine initiation among sons was correlated with child's age and race, household income, and the use of other vaccines. Vaccine initiation was higher for boys who were older (13-15 years old vs. 11-12 years old) (multivariate odds ratio [OR] = $3.34,95 \% \mathrm{CI}, 1.16-9.67)$ and whose race was neither white nor black (OR $=3.26,95 \% \mathrm{CI}$, 1.06-10.04), but initiation was lower for sons who lived in households with annual incomes greater than $\$ 50,000(\mathrm{OR}=0.22,95 \% \mathrm{CI}, 0.09-0.53)$. $\mathrm{HPV}$ vaccination was more common among sons who had received meningococcal vaccine ( $\mathrm{OR}=7.98,95 \% \mathrm{CI}, 3.70-17.21)$ or whose parents had received flu vaccine $(2.47,95 \% \mathrm{CI}, 1.05-5.84)$. Although non-Hispanic black race was also associated with HPV vaccine initiation in the bivariate analysis (OR = $4.71,95 \%$ CI, $1.88-11.84$ ), this relationship lost statistical significance in the multivariate model ( $\mathrm{OR}=1.80,95 \% \mathrm{CI}, 0.76-4.30)$. Post-hoc mediation analysis suggested that all four variables in the final model contributed to this reduction in the odds ratio for black race: household income (31\% reduction), boys' use of meningococcal vaccine (27\%), boys' age $(26 \%)$, and parents' use of flu vaccine $(16 \%)$.

HPV vaccine initiation among daughters was correlated with child's age, school type, and meningococcal vaccination status, in bivariate and multivariate analyses (Tables 2 and 3). Compared to 11-12 year olds, HPV vaccination was more common among 13-15 year olds $(\mathrm{OR}=2.21,95 \% \mathrm{CI}, 1.12-4.36)$ and $16-17$ year olds $(\mathrm{OR}=3.24,95 \% \mathrm{CI}, 1.52-6.91)$. HPV vaccine initiation was lower among girls attending private or home school rather than public school $(\mathrm{OR}=0.30,95 \% \mathrm{CI}, 0.12-0.71)$, and higher among those who had received meningococcal vaccine $(\mathrm{OR}=2.36,95 \% \mathrm{CI}, 1.36-4.10)$.

\section{Missed Opportunities}

Among adolescents who had not initiated HPV vaccination, most had missed an opportunity to receive vaccine. In the case of unvaccinated boys $(n=316), 84 \%$ had received a preventive care visit in the 12 months prior to the survey. Among the remaining 53 boys without a recent visit, $16 \%$ had received meningococcal vaccine, indicating some prior engagement with the healthcare system during adolescence. In the case of unvaccinated girls $(n=218)$, $79 \%$ had received a recent preventive visit, and among the remaining 52 girls without a recent visit, $25 \%$ had received meningococcal vaccine. In all, $87 \%$ of boys $(\mathrm{n}=276)$ and $84 \%$ of girls $(n=176)$ had missed the opportunity to receive HPV vaccine in the course of a recent preventive visit or along with meningococcal vaccine.

\section{Reasons for Not Getting HPV Vaccine}

Parents of unvaccinated sons and daughters commonly reported one of 7 different reasons for not getting their child HPV vaccine (Figure 2). Parents of sons were more likely than those of daughters to indicate their main reason was not receiving a provider's recommendation ( $27 \%$ versus $14 \%)$ or being unaware that HPV vaccine was available for their child's sex $(17 \%$ versus $0 \%)(p<0.01)$. Parents of daughters were more likely than those of sons to report concerns about vaccine safety or side effects as their main reason $(19 \%$ versus $7 \%)(p<0.01)$. 


\section{DISCUSSION}

In this statewide sample of parents in North Carolina, we found that correlates and concerns related to HPV vaccine initiation differed for boys and girls. With $14 \%$ of parents of sons reporting initiation, this study suggests uptake among boys has increased in North Carolina beyond previously reported national estimates [11,12], but is still very low. Initiation among boys was linked to other vaccine use by the child and parent, and was also correlated with boys' demographic characteristics, such that sons from lower-income and minority (nonwhite and non-black) backgrounds received HPV vaccine more often. This pattern of initiation may be due to greater vaccine acceptability in these populations [4] or to increased access to vaccines through Vaccines for Children (VFC), a program that provides vaccines at no cost to uninsured, underinsured, and Medicaid-insured youth as well as to American Indians and Alaska Natives [22].

Although both explanations are plausible, we suspect that North Carolina's VFC program played an especially important role in increasing HPV vaccine uptake among North Carolina boys beyond national estimates. In 2010, approximately one-third of first doses of HPV vaccine funded by the program were administered to boys (A. Dayton, personal communication, July 3,2012 ). Our hypothesis is also partially supported by our finding that two variables we would expect to correspond to VFC participation, household income and boys' use of meningococcal vaccine, mediated much of the relationship between black race and HPV vaccination. Whatever the mechanism, vaccine initiation among adolescents from low-income and minority backgrounds is encouraging given that these populations are at risk for experiencing cancer-related health disparities later in life [23].

With $44 \%$ of parents reporting their daughter received one or more doses of HPV vaccine, this study's estimate of initiation among girls is comparable to other state and national estimates. For example, the 2010 National Immunization Survey (NIS)-Teen found that about half (52\%) of adolescent females in North Carolina had initiated HPV vaccine, a figure close to the national average of $49 \%$ [12]. Unlike NIS-Teen, our study included 11- to 12 -year-olds who were still in the target age range for routine vaccination. When we excluded this younger group, our analysis placed initiation at 50\%, in line with NIS-Teen findings. Compared to sons, initiation among daughters was less strongly or consistently associated with other vaccine use. Girls' initiation was not directly correlated with demographic characteristics, but did vary by school type with private- or home-schooled girls less often receiving HPV vaccine. Furthermore, unlike an analysis of $2008 \mathrm{NC}$ CHAMP data [13], we did not find disparities in HPV vaccination related to healthcare utilization or rural residence. This good news is tempered by our finding that girls' overall initiation level improved only modestly from $31 \%$ in 2008 [13].

Given that our findings are based on data collected in 2010 before the CDC issued recommendations for routine vaccination of boys against HPV, the difference in coverage we observed between sons and daughters in our sample is not surprising. However, the differences we found in correlates of initiation by sex is unexpected. Age and other vaccine use were correlates for both groups, but demographic characteristics related to lower income and minority race were associated with HPV vaccine initiation for boys, but not girls. These differences are even more pronounced when our correlates for boys are compared to early correlates for girls. As previously mentioned, an analysis of 2008 NC CHAMP data found that girls' initiation of HPV vaccine two years post-licensure was characterized by health disparities, and girls were less likely to get the vaccine if they lacked a regular healthcare provider, had not had a recent preventive visit, lived in a rural county, or if the parent responding to the questionnaire was unemployed [13]. In other words, while early HPV 
initiation among boys seems to have been more common among at-risk populations, the opposite appears to have been true for girls.

These differences in who first adopts HPV vaccine suggest an interaction between sex and other demographic characteristics that is likely related to the female-specific approach of early HPV vaccination efforts. For example, it may be that socially-advantaged parents are more influenced than others by practice recommendations and marketing efforts [24], which extolled the benefits of HPV vaccination for girls soon after licensure, but which in 2010 had focused much less extensively on boys. Alternatively, concerns about HPV vaccine safety may differ such that lower income and minority parents harbor safety concerns more often for girls than for boys. Differential patterns of healthcare use by adolescents could also contribute to differences in uptake since, compared to females, adolescent males seek preventive care less often and in different venues, thereby decreasing the influence of having a regular healthcare provider on HPV vaccination for boys $[25,26]$.

The CDC's new guidelines should raise awareness of HPV vaccination for boys among healthcare providers and in the general public. In addition, the guidelines are likely to increase boys' access to HPV vaccine as private insurers typically cover the cost of vaccines recommended for routine use [2]. Although these factors will no doubt improve uptake among boys to some extent, the experience of girls suggests that attaining the widespread coverage needed to achieve population-level protection will require a more concerted effort.

Toward this end, our findings have implications for practitioners as they seek to address very low levels of vaccine initiation among boys. First, our findings underscore the importance of healthcare provider recommendation of HPV vaccine $(14-16,27)$. When asked why they had not gotten HPV vaccine for their child, almost half (44\%) of parents of unvaccinated sons reported they were either unaware the vaccine was available for boys or that their provider had not recommended it. Second, compared to daughters, HPV vaccine initiation among sons was more closely linked to the use of other vaccines, suggesting that providing HPV vaccine concomitant with other adolescent vaccines may be particularly important in this population. Given that parents in our sample reported a high degree of engagement with the healthcare system, providers are well positioned for meeting families' informational needs and for integrating HPV vaccination into the processes of routine care.

Finally, we were interested to see that parents of sons less often reported concerns about safety and side effects as their main reason for not getting their child vaccinated against HPV. Because so many parents in our sample were unaware HPV vaccine was available for boys, we cannot yet conclude that perceptions about vaccine safety will present less of a barrier in the vaccination of boys. However, future studies should consider whether perceived harms related to HPV vaccine differ by child's sex.

This study has several strengths, including the use of a large population-based sample of parents and the ability to conduct interviews with Spanish-speaking as well as Englishspeaking parents. Limitations include the cross-sectional study design and parental report of HPV vaccine initiation. However, parental recall of HPV vaccination may be more accurate than recall for other types of vaccines [28]. The CHAMP survey did not assess some factors that are important for HPV vaccination, such as anticipated regret, perceived risk of getting HPV-related diseases, and perceived barriers to vaccination [14-15]. Additionally, parents in our study were more educated than the state as a whole [29], and our sample was restricted to respondents with a landline phone. For these reasons, our results may be somewhat less generalizable to less educated, low-income, rural, and minority populations, even after weighting [30]. 
In North Carolina, HPV vaccine initiation levels among adolescent girls have consistently mirrored the national average. This study provides preliminary information about the prevalence and correlates of HPV vaccine initiation among boys, and tracking uptake in this population will be important for evaluating the state's success at meeting recommendations for the routine vaccination of boys. Based on our statewide sample of parents, our findings suggest that provider recommendation of HPV vaccine alongside other vaccines is a cancer prevention strategy that may be particularly well suited for improving the very low level of coverage among boys.

\section{Acknowledgments}

This study was supported by GlaxoSmithKline, the Cancer Control Education Program at UNC Lineberger Comprehensive Cancer Center (R25 CA57726), and a NRSA in Primary Medical Care at the University of Minnesota (T32HP22239). NB has received HPV vaccine-related grants from or been on advisory boards for GlaxoSmithKline and Merck.

The authors wish to thank Vito DiBona at the North Carolina State Center for Health Statistics as well as Amanda Dayton and Beth Quinn at the North Carolina Division of Public Health for their assistance.

\section{References}

1. Markowitz LE, Dunne EF, Saraiya M, Lawson HW, Chesson H, Unger ER. Quadrivalent human papillomavirus vaccine: recommendations of the Advisory Committee on Immunization Practices (ACIP). MMWR Recomm Rep. 2007; 56(RR02):1-24. [PubMed: 17380109]

2. Centers for Disease Control and Prevention. ACIP recommends all 11-12 year-old males get vaccinated against HPV. 2011. Available at: http://www.cdc.gov/media/releases/2011/t1025_hpv_12yroldvaccine.html

3. Reiter PL, McRee AL, Gottlieb SL, Brewer NT. HPV vaccine for adolescent males: acceptability to parents post-vaccine licensure. Vaccine. 2010; 28:6292-7. [PubMed: 20637770]

4. Liddon N, Hood J, Wynn BA, Markowitz LW. Acceptability of human papillomavirus vaccine for males: a review of the literature. J Adolesc Health. 2010; 46(2):113-23. [PubMed: 20113917]

5. Wheldon CW, Daley EM, Buhi ER, Nyitray AG, Giuliano AR. Health beliefs and attitudes associated with HPV vaccine intention among young gay and bisexual men in the southeastern United States. Vaccine. 2011; 29(45):8060-5. [PubMed: 21864615]

6. Katz ML, Krieger JL, Roberto AJ. J Mens Health. 2011; 8(3):175-84. [PubMed: 21966351]

7. Jones M, Cook R. Intent to receive an HPV vaccine among university men and women and implications for vaccine administration. J Am Coll Health. 2008; 57:23-32. [PubMed: 18682342]

8. Ferris DG, Waller JL, Miller J, Patel P, Jackson L, Price GA, et al. Men's attitudes toward receiving the human papillomavirus vaccine. J Low Genit Tract Dis. 2008; 12:276-81. [PubMed: 18820541]

9. Ferris DG, Waller JL, Miller J, Patel P, Price GA, Jackson L, et al. Variable associated with human papillomavirus (HPV) vaccine acceptance by men. J Am Board Fam Med. 2009; 22:34-42. [PubMed: 19124631]

10. Gerend MA, Barley J. Human papillomavirus vaccine acceptability among young adult men. Sex Transm Dis. 2009; 36:58-62. [PubMed: 18830138]

11. Reiter PL, McRee AL, Kadis JA, Brewer NT. HPV vaccine and adolescent males. Vaccine. 2011; 29:5595-602. [PubMed: 21704104]

12. Centers for Disease Control and Prevention. National and state vaccination coverage among adolescents aged 13 through 17 years--United States, 2010. MMWR. 2011; 60(33):1117-23. [PubMed: 21866084]

13. Reiter PL, Cates JR, McRee AL, Gottlieb SL, Shafer A, Smith JS, et al. Statewide HPV vaccine initiation among adolescent females in North Carolina. Sex Transm Dis. 2010; 37(9):549-56. [PubMed: 20414146]

14. Reiter PL, Brewer NT, Gottlieb SL, McRee AL, Smith JS. Parents' health beliefs and HPV vaccination of their adolescent daughters. Soc Sci Med. 2009; 69:475-80. [PubMed: 19540642] 
15. Brewer NT, Gottlieb SL, Reiter PL, McRee AL, Liddon N, Markowitz L, et al. Longitudinal predictors of human papillomavirus vaccine initiation among adolescent girls in a high-risk geographic area. Sex Trans Dis. 2011; 38(3):197-204.

16. Gottlieb SL, Brewer NT, Sternberg MR, Smith JS, Ziarnowski K, Liddon N, et al. Human papillomavirus vaccine initiation in an area with elevated rates of cervical cancer. J Adolesc Health. 2009; 45:430-7. [PubMed: 19837348]

17. Wong CA, Berkowitz Z, Dorell CG, Anhang Price R, Lee J, Saraiya M. Human papillomavirus vaccine uptake among 9- to 17-year-old girls: National Health Interview Survey, 2008. Cancer. 2011; 117(24):5612-20. [PubMed: 21692069]

18. North Carolina State Center for Health Statistics. Behavioral Risk Factor Surveillance System (BRFSS). 2011. Available at: http://www.epi.state.nc.us/SCHS/brfss/

19. North Carolina State Center for Health Statistics. Child Health Assessment and Monitoring Program (CHAMP). 2011. Available at: http://www.epi.state.nc.us/SCHS/champ/

20. Centers for Disease Control and Prevention. Behavioral Risk Factor Surveillance System: 2010 summary data quality report. 2011. Available at: ftp://ftp.cdc.gov/pub/Data/Brfss/2010_Summary_Data_Quality_Report.pdf

21. U.S. Census Bureau. Metropolitan and micropolitan statistical areas. 2011. Available at: http://www.census.gov/population/metro/

22. Centers for Disease Control and Prevention. Vaccines for Children Program (VFC). 2011. Available at: http://www.cdc.gov/vaccines/programs/vfc/default.htm

23. Siegel R, Ward E, Brawley O, Jemal A. Cancer statistics, 2011. CA Cancer J Clin. 2011; 61:21236. [PubMed: 21685461]

24. Hughes J, Cates JR, Liddon N, Smith JS, Gottlieb SL, Brewer NT. Disparities in how parents are learning about the human papillomavirus vaccine. Cancer Epidemiol Biomarkers Prev. 2009; 18:363-72. [PubMed: 19190161]

25. Marcell AV, Klein JD, Fischer I, Allan MJ, Kokotailo PK. Male adolescent use of health care services: where are the boys? J Adolesc Health. 2002; 30:35-43. [PubMed: 11755799]

26. Rand CM, Shone LP, Albertin C, Auinger P, Klein JD, Szilagyi PG. National health care visit patterns of adolescents: Implications for delivery of new adolescent vaccines. Arch Pediatr Adolesc Med. 2007; 161:252-9. [PubMed: 17339506]

27. Brewer NT, Fazekas K. Predictors of HPV vaccine acceptability: a theory-informed, systematic review. Prev Med. 2007; 45:107-14. [PubMed: 17628649]

28. Dorell CG, Jain N, Yankey D. Validity of parent-reported vaccination status for adolescents aged 13-17 years: National Immunization Survey-Teen, 2008. Public Health Rep. 2011; 126(S2):60-9. [PubMed: 21812170]

29. U.S. Census Bureau. American Community Survey. 2010. Available at: http://factfinder2.census.gov/faces/tableservices/jsf/pages/productview.xhtml?src=bkmk

30. Miles, DR.; Herrick, H.; Ford, CA. North Carolina Department of Health and Human Services, Division of Public Health. Statistical Primer: A Publication of the State Center for Health Statistics. 2010. The North Carolina Child Health Assessment and Monitoring Program: survey methodology and data collection; p. 181-14. 


\section{Highlights}

We assessed HPV vaccine initiation in a population-based sample of adolescents.

Only $14 \%$ of boys had initiated HPV vaccine compared to $44 \%$ of girls.

For both sexes, initiation correlated with age and use of meningococcal vaccine.

For boys, initiation correlated with lower income and non-black/non-white race.

For girls, in was itiation associated with public school attendance. 


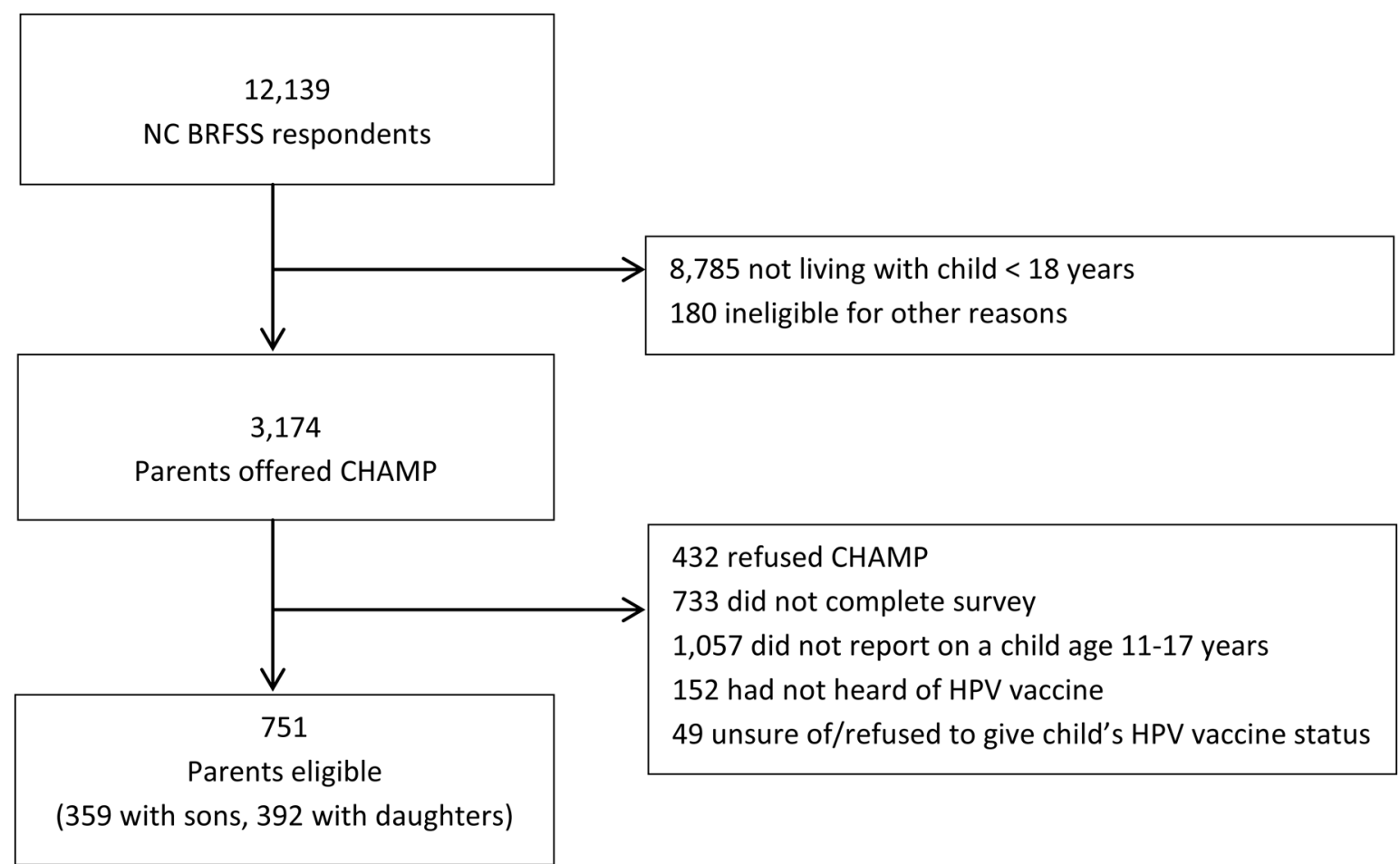

Figure 1.

Study sample 


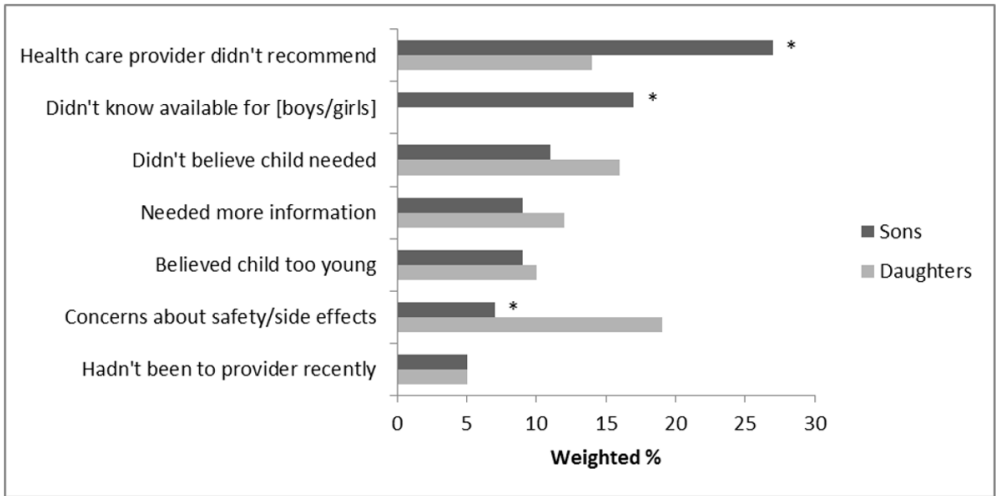

Figure 2.

Main reason for not getting son or daughter HPV vaccine $* p<0.01$ 
Table 1

Child, parent, and household characteristics for sons $(n=359)$ and daughters $(n=392){ }^{a}$

\begin{tabular}{|c|c|c|}
\hline & $\begin{array}{l}\text { Sons } \\
\text { n (\%) }\end{array}$ & $\begin{array}{c}\text { Daughters } \\
\text { n }(\%)\end{array}$ \\
\hline \multicolumn{3}{|l|}{ Child characteristics } \\
\hline \multicolumn{3}{|l|}{ Age (years) } \\
\hline $11-12$ & $88(28)$ & $100(29)$ \\
\hline $13-15$ & $160(42)$ & $172(44)$ \\
\hline $16-17$ & $111(30)$ & $120(27)$ \\
\hline \multicolumn{3}{|l|}{ Race } \\
\hline Non-Hispanic white & $261(71)$ & $289(67)$ \\
\hline Non-Hispanic black & $61(19)$ & $58(20)$ \\
\hline Other & $37(10)$ & $45(13)$ \\
\hline \multicolumn{3}{|l|}{ School type ${ }^{b}$} \\
\hline Public & $313(89)$ & $351(90)$ \\
\hline Private/home schooled & $43(11)$ & $41(10)$ \\
\hline \multicolumn{3}{|l|}{ Health insurance coverage } \\
\hline No/don't know & $20(4)$ & $27(7)$ \\
\hline Yes & $339(96)$ & $365(93)$ \\
\hline \multicolumn{3}{|l|}{ Regular healthcare provider } \\
\hline No/don't know & $67(19)$ & $65(17)$ \\
\hline Yes & $292(81)$ & $327(83)$ \\
\hline \multicolumn{3}{|l|}{ Preventive check-up in the last year } \\
\hline No/don't know & $55(14)$ & $75(20)$ \\
\hline Yes & $304(86)$ & $317(80)$ \\
\hline \multicolumn{3}{|l|}{ Parent characteristics } \\
\hline \multicolumn{3}{|l|}{ Age (years) } \\
\hline$\leq 39$ & $94(29)$ & $88(26)$ \\
\hline $40-49$ & $166(47)$ & $203(52)$ \\
\hline$\geq 50$ & $99(24)$ & $101(22)$ \\
\hline \multicolumn{3}{|l|}{ Sex } \\
\hline Female & $312(86)$ & $346(90)$ \\
\hline Male & $47(14)$ & $46(10)$ \\
\hline \multicolumn{3}{|l|}{ Employment status } \\
\hline Employed for wages/self-employed & $256(70)$ & $274(68)$ \\
\hline Other (unemployed, homemaker, student, retired, unable to work) & $103(30)$ & $118(32)$ \\
\hline \multicolumn{3}{|l|}{ Household characteristics } \\
\hline \multicolumn{3}{|l|}{ Annual income } \\
\hline$<\$ 50,000$ & $132(38)$ & $136(37)$ \\
\hline$\geq \$ 50,000$ & $200(54)$ & $216(54)$ \\
\hline Not reported & $27(8)$ & $40(10)$ \\
\hline Highest education & & \\
\hline
\end{tabular}




\begin{tabular}{lcc}
\hline & $\begin{array}{c}\text { Sons } \\
\mathbf{n}(\%)\end{array}$ & $\begin{array}{c}\text { Daughters } \\
\mathbf{n}(\%)\end{array}$ \\
\hline High school or less & $59(19)$ & $70(18)$ \\
$\quad$ Some college or more & $300(81)$ & $322(82)$ \\
Number of children & & \\
1 & $164(28)$ & $183(32)$ \\
$\geq 2$ & $195(72)$ & $209(68)$ \\
Urbanicity & & \\
Rural & $85(28)$ & $93(24)$ \\
Urban & $274(72)$ & $299(76)$ \\
\hline
\end{tabular}

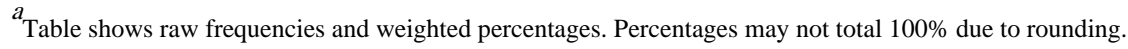

${ }^{b}$ Excludes parents who indicated that they did not know their child's school type ( $\mathrm{n}=1$ son), that their child was not in school ( $\mathrm{n}=1$ son), or who refused to answer ( $\mathrm{n}=1$ son). 


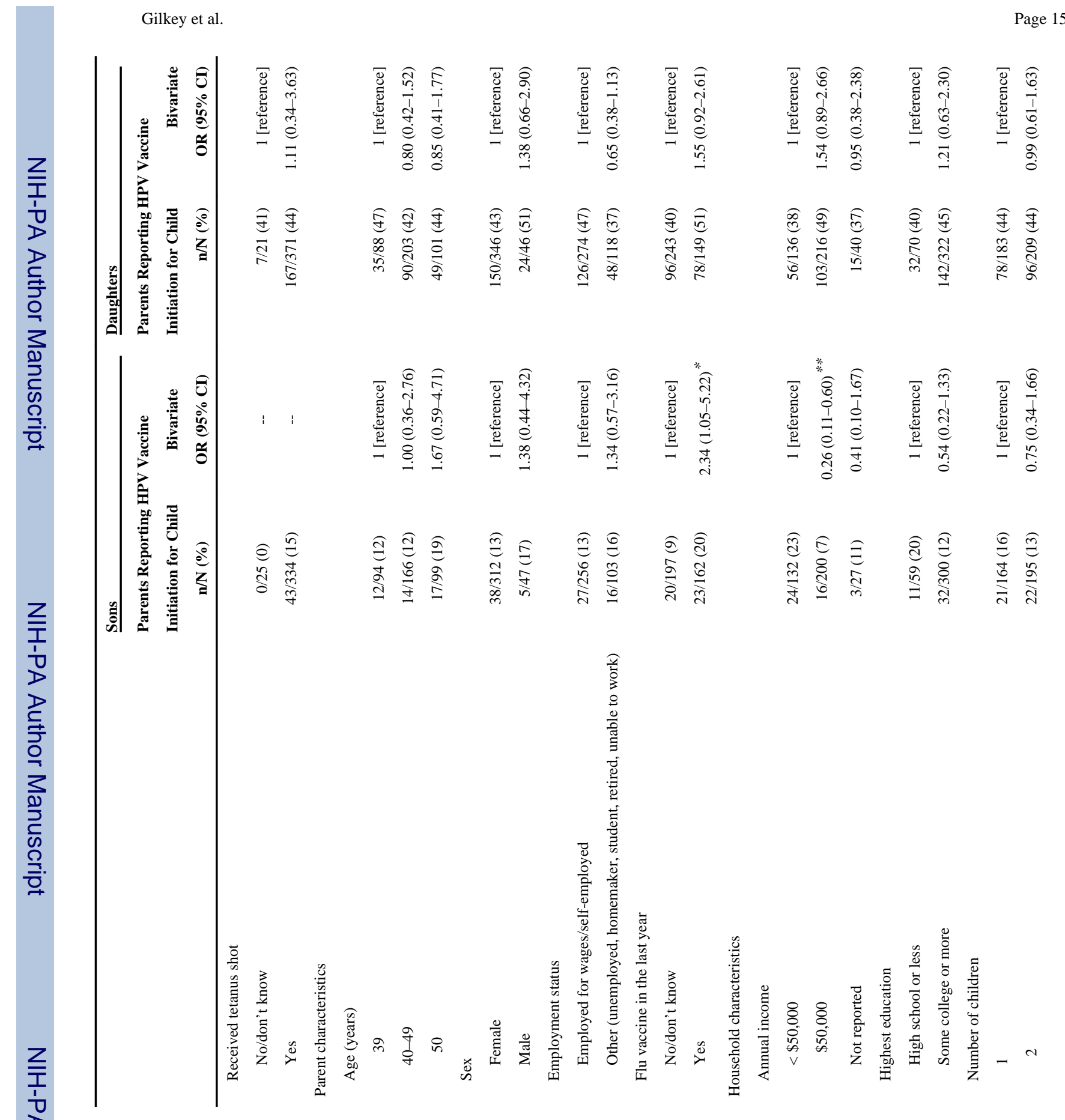




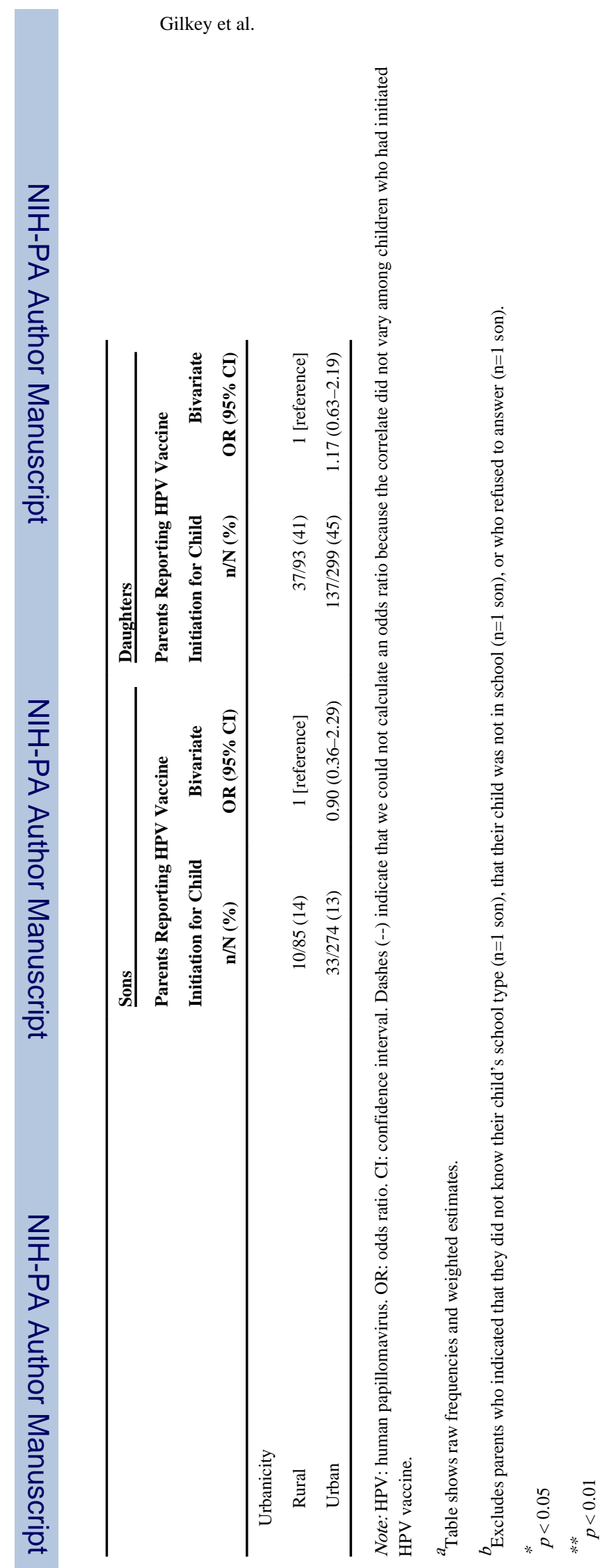

Vaccine. Author manuscript; available in PMC 2013 September 07. 


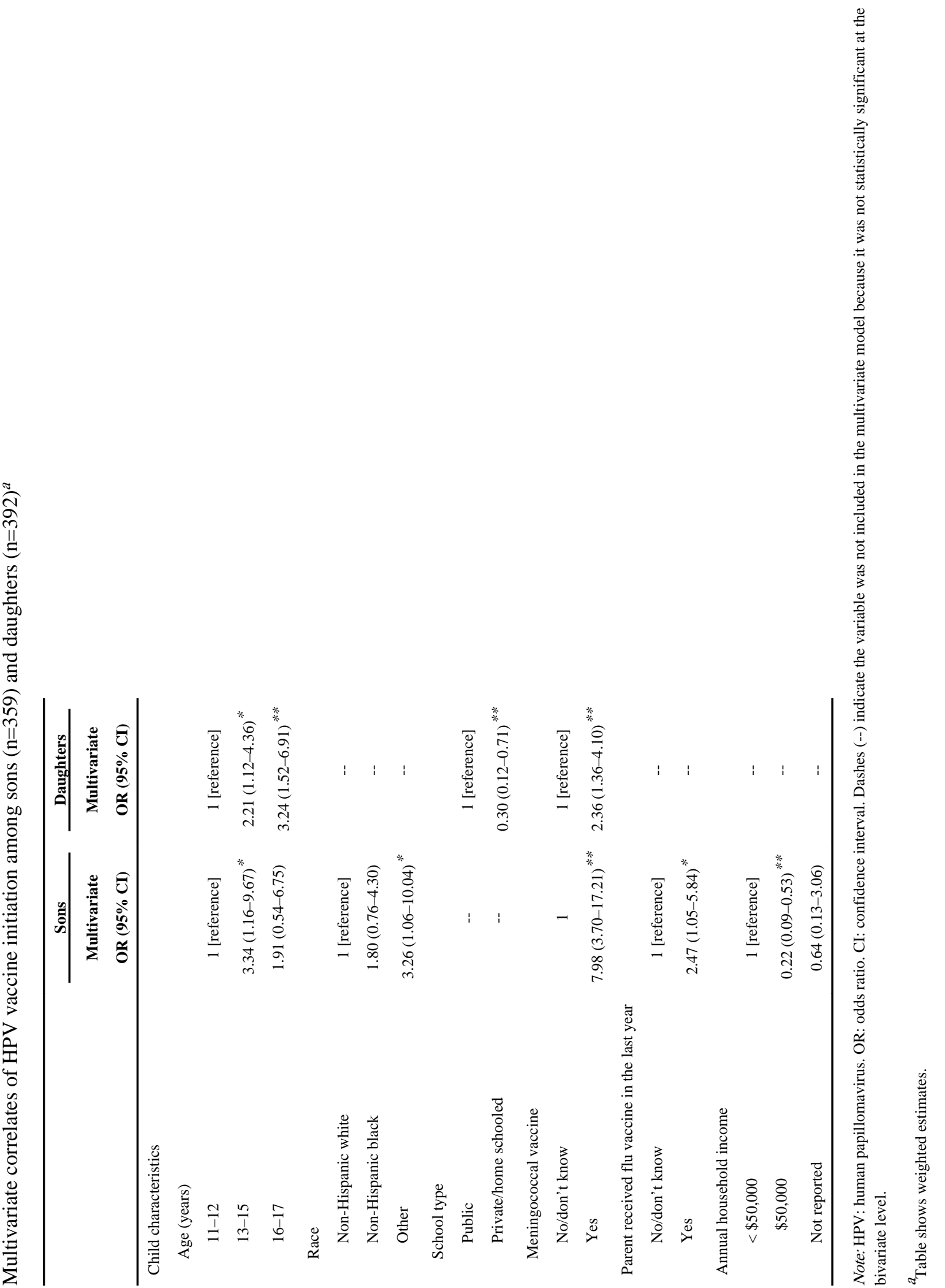




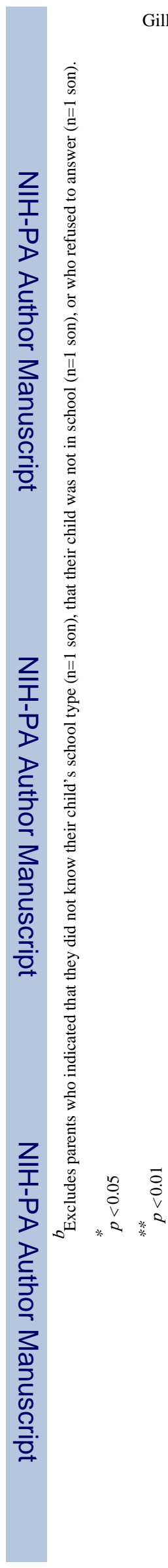

Vaccine. Author manuscript; available in PMC 2013 September 07. 